(Teknologi Rekayasa Jaringan Telekomunikasi) : Jurnal Teknik Elektro

Volume 1, Nomor 1, April 2021

DOI: https://doi.org/10.51510/trekritel.v1i1.399

\title{
Miniatur Rancang Bangun Penerangan Lampu Jalan Otomatis Pada Malam Hari Menggunakan Sensor Ultrasonik Berbasis Arduiono Mega
}

\author{
Maharani Syafira Lubis, Yosepin Sihotang \\ Program Studi Teknik Telekomunikasi \\ Politeknik Negeri Medan \\ Jl. Almamater, No. 1 Medan Telp. (061) 8211235, Kode Pos 20155, Indonesia \\ e-mail: maharanisl@gmail.com
}

\begin{abstract}
Abstrak-Hampir setiap hari lampu penerangan jalan selalu dengan kondisi menyala, sehingga ketahanannya dapat berkurang sampai lampu tersebut mengalami keadaan rusak dan kondisi mati. Hal ini disebabkan bahwa penggunaan lampu jalan tersebut dapat mengakibatkan pemborosan terhadap energi listrik. hari. Seharusnya tindakan yang dilakukan dalam mencegah pemborosan energi listrik yaitu dengan memulai penghematan listrik. Pencegahan ini harus dimulai sejak dini hari, agar bertujuan untuk kebaikan kita bersama di masa yang akan datang. Melalui masalah tersebut, maka dapat dilakukan dengan membuat suatu perancangan yang menggunakan sistem teknologi. Sistem teknologi yang dirancang ialah dengan membuat lampu penerangan jalan otomatis, yang dikendalikan oleh Mikrokontroler Arduino Mega dan Sensor Ultrasonic. Relay dan Sensor Ultrasonik menggunakan arus yang ada di dalam Arduino, Arduino memiliki kerja sebesar 5v. Untuk penggunaan Relay ini berfungsi sebagai pengendali sedangkan arusnya terpisah. Pemakaian Baterai juga digunakan dalam rancang bangun ini yaitu agar dapat menghidupkan LED yang sedang digunakan sebagai contoh lampu otomatis yang ada pada rancang bangun lampu otomatis tersebut. Untuk cara kerja lampu otomatis tersebut adalah dengan membaca sensor Ultrasonic dari sebuah kendaraan sehingga dapat menghidupkan lampu dan Relay yang digunakan, sampai kepada untuk menghidupkan arus. Kemudian apabila ada bentuk pergerakan, maka relay mengalami keadaan menyala dan otomatis lampu dengan kondisi ON. Jadi jika sebuah kendaraan bergerak menuju lampu penerangan tersebut maka lampu tersebut akan otomatis menyala dan menerangi jalan, sehingga setelah kendaraan tersebut lewat maka lampu tersebut akan otomatis mati agar dapat menghemat arus listrik pada area jalan.
\end{abstract}

Kata kunci : Arduino Mega, Sensor ultrasonic, Lampu LED

\begin{abstract}
Almost every day the street lighting is always on, so that its durability can be reduced until the lamp is damaged and in a dead condition. This is due to the fact that the use of these street lights can result in a waste of electrical energy. day. Action should be taken to prevent waste of electrical energy, namely by starting electricity savings. This prevention must start early in the morning, so that it aims for our common good in the future. Through this problem, it can be done by making a design that uses a technology system. The technology system designed is to make automatic street lighting, which is controlled by the Arduino Mega Microcontroller and Ultrasonic Sensor. Ultrasonic Relays and Sensors use the current in the Arduino, Arduino has a work of 5v. For use, this relay functions as a controller while the current is separate. Battery usage is also used in this design, namely in order to turn on the LED which is being used as an example of an automatic lamp in the automatic lamp design. For the way the automatic light works is to read the Ultrasonic sensor of a vehicle so that it can turn on the light and relay. used, to turn on the current. Then if there is a form of movement, the relay will turn on and automatically the lights are ON. So if a vehicle moves towards the lighting, the light will automatically turn on and illuminate the road, so that after the vehicle passes, the light will automatically turn off in order to save electricity in the road area.
\end{abstract}

Keywords : Arduino Mega, Ultrasonic sensor, LED light 


\section{Pendahuluan}

Perkembangan teknologi dari jaman ke jaman terhadap listrik sudah menjadi keputuhan pokok bagi manusia, khususnya dengan perubahan teknologi pada listrik semakin canggih. Peningkatan penambahan daya listrik dapat mengakibatkan beban tambahan, sehingga semakin modern nya abad maka semakin borosnya penggunaan energi listrik yang dikelola. Seperti hal nya pemborosan pada energi listrik terhadap pemakaian lampu dijalan raya, hal ini harus diupayakan pencegahan terhadap pasokan listrik PLN yang terbatas. Penghematan energi listrik akan berguna untuk menguntungkan pihak konsumen dan produsen pengelola. Dari penelitian ini akan diambil sebuah topik tentang perancangan saklar otomatis terhadap sensor gerak yang akan mendeteksi kehadiran suatu kendaraan yang mendekati sensor tersebut dengan mendeteksi kuatnya suatu intensitas. Pada saat lampu penerangan jalan mengalami keadaan menyala secara otomatis, maka ada bentuk kendaraan yang sedang melewati lampu jalan tersebut. Kemudian apabila kendaraan sudah melewati lampu jalan tersebut, maka secara otomatis juga lampu akan kembali mengalami keadaan mati. Dengan kata lain bahwa sensor sedang mengalami kehadiran suatu kendaraan yang lewat maka akan diaplikasikan sebagai saklar otomatis untuk menghidupkan lampu di jalan tersebut. Pengaturan lampu penerangan biasanya dengan menggunakan saklar dengan bekerja menghidupkan atau mematikan lampu melalui pengoperasian saklar secara manual. Lampu jalan sering sekali dilihat sendang keadaan menyala selama satu harian, apabila hal tersebut terjadi dalam waktu yang lama maka ha itu termasuk kedalam suatu pemborosan terhadap energi listrik. Sehingga dengan menghindari pemborosan energi listrik tersebut, maka dalam penelitian ini dirancang dan dibahas tentang rangkaian otomatis lampu jalan raya yang biasanya gunakan pada saat malam hari tiba.

\section{STUDI PUSTAKA}

\section{A. Mikrokontroler}

Penggunaan Mikrokontroler akan berfungsi sebagai alat pengontrol rangkaian elektronik serta dapat menyimpan suatu program didalamnya. Mikrokontroler pada umumnya terdiri dari CPU (Central Processing Unit), memori yaitu RAM ( Random Access Memory ), ROM ( Read Only Memory ), I/O tertentu dan unit pendukung seperti Analog-to-Digital Converter (ADC) yang sudah terintegrasi di dalamnya. Mikrokontroler biasanya hanya bisa digunakan pada aplikasi tertentu dan dapat menyimpan satu program saja. Adapun perbandingan dari RAM dan ROM nya yaitu pada program-program pengguna disimpan dalam ruang RAM yang relatif besar, sedangkan rutin-rutin antarmuka perangkat keras disimpan dalam ruang ROM yang kecil.

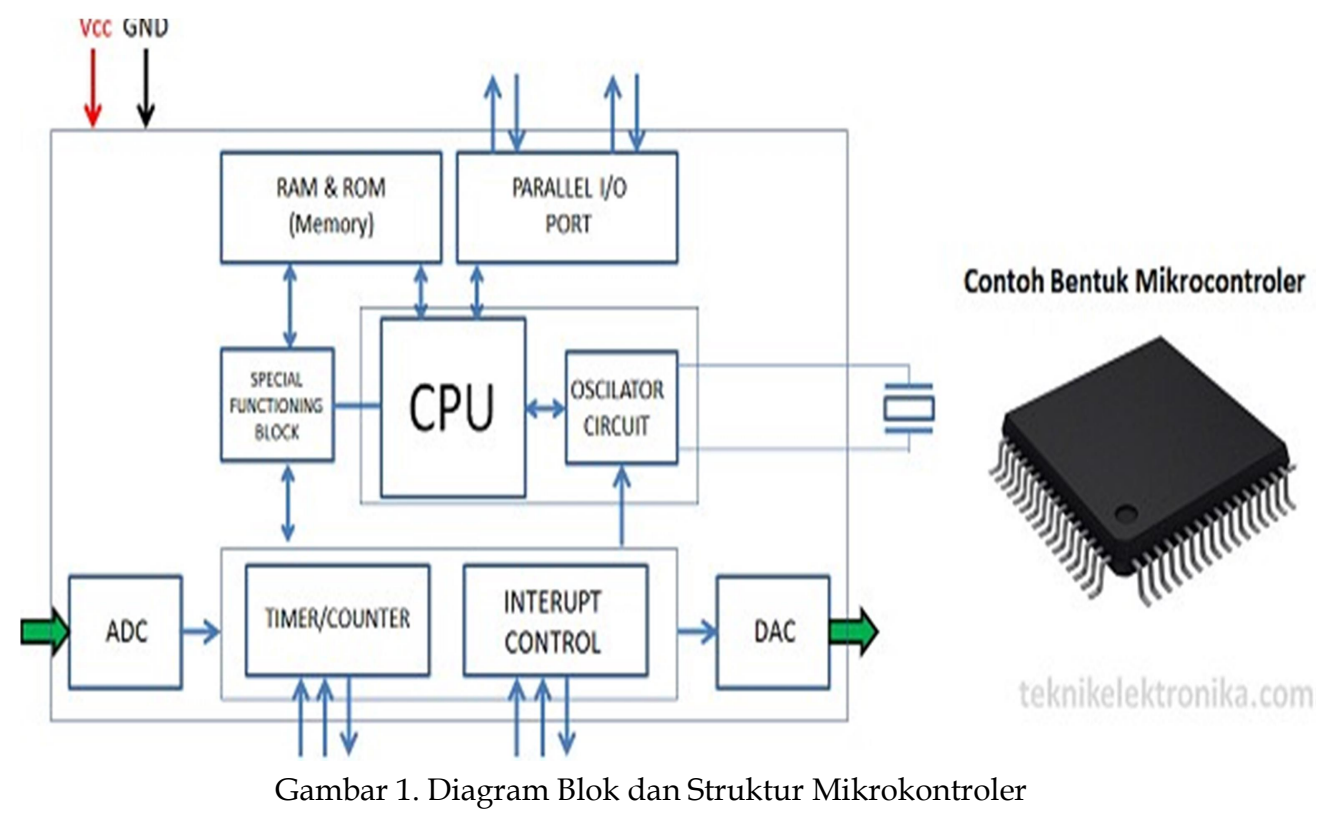

Copyright $^{\oplus} 2021$ TRekRiTel (Teknologi Rekayasa Jaringan Telekomunikasi) : Jurnal Teknik Elektro.

This is an open acces article under the CC-BY-SA lisence (https://creativecommons.org/licenses/by-sa/4.0/). 


\section{Keterangan :}

1. Penggunaan CPU merupakan otak dari mikrokontroler, yang berfungsi untuk mengambil instruksi (fetch), menerjemahkannya (decode), lalu akhirnya dieksekusi (execute). CPU menghubungkan setiap bagian dari mikrokontroler ke dalam satu sistem. Fungsi utama CPU adalah mengambil dan mendekode instruksi. Instruksi yang diambil dari memori program harus diterjemahkan atau melakukan decode oleh CPU tersebut.

2. Penggunaan memori yang berfungsi untuk menyimpan data-data dan membuat program aplikasi. biasanya memiliki sejumlah RAM dan ROM (EEPROM, EPROM dan lain- lainnya) atau memori flash untuk menyimpan kode sumber program (source code program).

3. Penggunaan Port Input / Output paralel yang berfungsi untuk menghubungkan dari berbagai perangkat seperti LCD, LED, printer, memori dan perangkat INPUT/OUTPUT lainnya ke mikrokontroler.

4. Penggunaan Port serial akan berfungsi untuk menyediakan antarmuka serial antara mikrokontroler dan periferal lainnya.

5. Penggunaan Timer dan Counter akan berfungsi untuk mengatur dan menyediakan semua fungsi terhadap waktu dan penghitungan di dalam mikrokontroler. Operasi utama yang dipakai adalah fungsi jam, modulasi, pembangkitan pulsa, pengukuran frekuensi, osilasi, dan lain sebagainya.

6. Penggunaan Konverter ADC akan berfungsi untuk mengubah sinyal analog ke bentuk digital, melalui sinyal input dalam konverter ini harus dalam bentuk analog (misalnya Output dari Sensor) sedangkan Outputnya dalam bentuk digital.

7. Penggunaan Konverter DAC akan berfungsi untuk mengubah sinyal digital menjadi format analog. Ini biasanya digunakan untuk mengendalikan perangkat analog seperti motor DC dan lain sebagainya.

8. Penggunaan Kontrol interupsi akan berfungsi untuk menyediakan interupsi (penundaan) untuk program kerja. Interrupt dapat berupa eksternal (diaktifkan dengan menggunakan pin interrupt) atau internal (dengan menggunakan instruksi interupsi selama pemrograman).

9. Penggunaan Mikrokontroler yang lainnya akan berfungsi untuk beberapa aplikasi khusus saja (misalnya sistem Robotik), dan pengontrol ini juga memiliki beberapa port tambahan dalam melakukan operasi khusus tersebut yang umumnya dinamakan dengan Blok Fungsi Khusus.

\section{B. Arduino Mega 2560}

Penggunaan Board Arduino Mega 2560 ini memiliki Pin I/O yang relatif banyak, 54 digital Input / Output, 15 buah di antaranya dapat di gunakan sebagai output PWM, 16 buah analog Input, 4 UART. Arduino Mega 2560 ini di lengkapi kristal 16 Mhz. Dalam Untuk penggunaannya sangat sederhana dengan cara menghubungkan power dari USB ke PC / Laptop atau melalui Jack DC memakai adaptor 7-12 V DC tersebut.

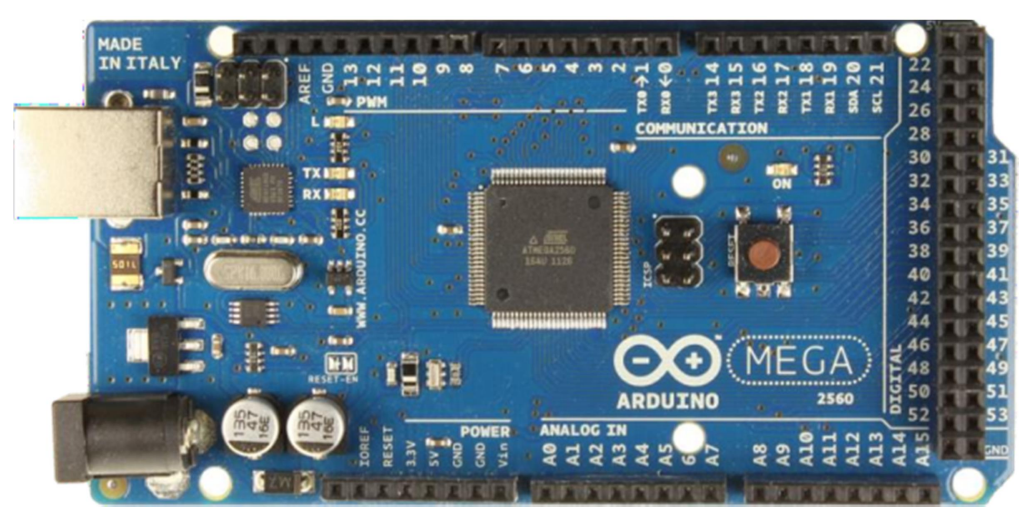

Gambar 2. Arduino Mega 2560 


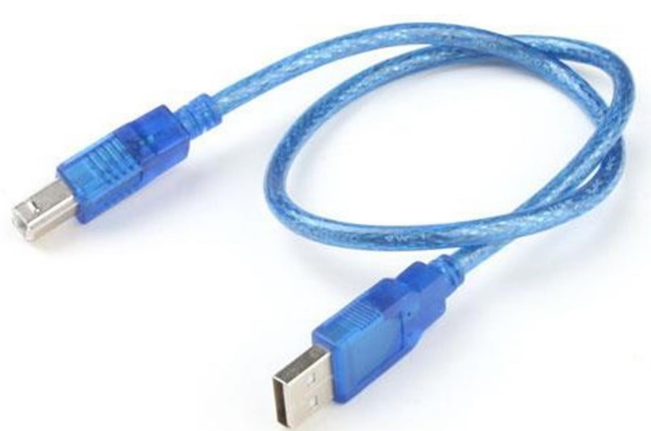

Gambar 3. Kabel USB Penghubung Arduino

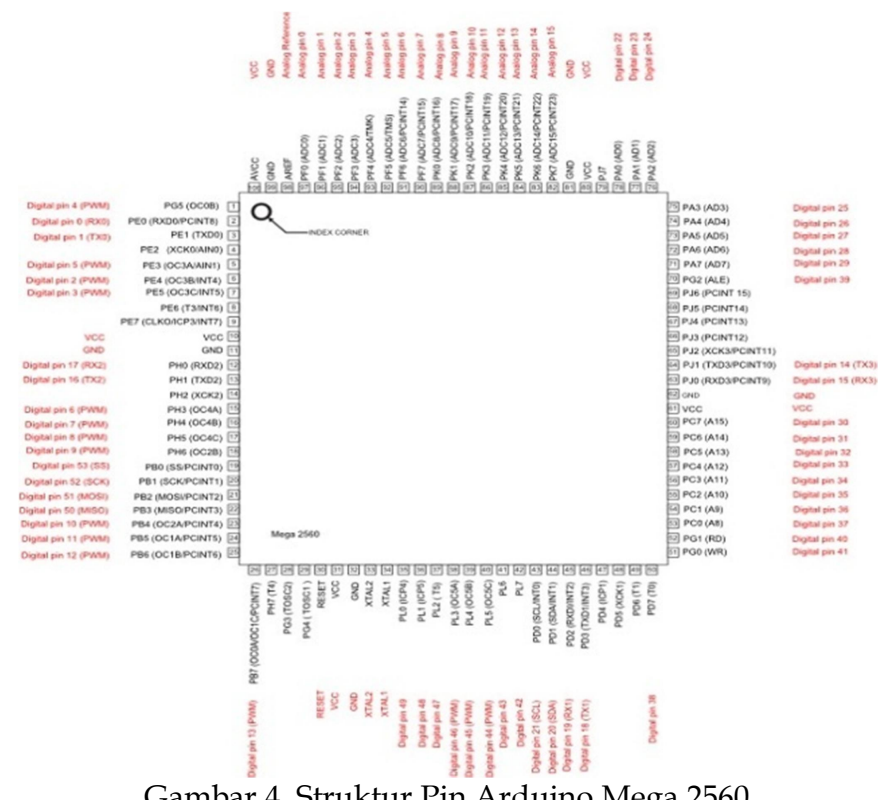

Gambar 4. Struktur Pin Arduino Mega 2560

\section{Sensor Ultrasonic HC-SR04}

Penggunaan Sensor Ultrasonic HC-SR04 akan berfungsi sebagai pengirim, penerima, dan pengontrol gelombang ultrasonik dan dapat digunakan juga untuk mengukur jarak benda dari $2 \mathrm{~cm}-$ $4 \mathrm{~m}$ dengan akurasi $3 \mathrm{~mm}$. Alat ini memiliki 4 pin, pin Vcc, Gnd, Trigger, dan Echo. Pin Vcc untuk listrik positif dan Gnd untuk ground-nya. Untuk Pin Trigger nya sebagai untuk pengeluar sinyal dari sensor dan pin Echo sebagai penangkap sinyal pantul dari benda tersebut.

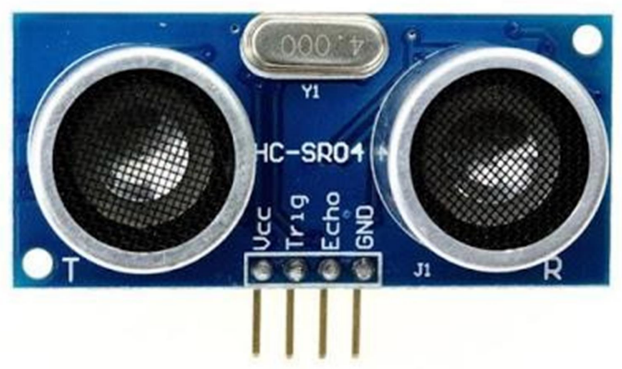

Gambar 5. Sensor Ultrasonik HC-SR04

Untuk cara kerja sensor Ultrasonic HC-SR04 dalam menghasilkan gelombang ultrasonik yang berfrekuensi $40 \mathrm{kHz}$, biasanya akan memancarkan gelombang pada suatu target dan apabila sudah mengenai permukaan target maka gelombang tersebut akan terpantulkan kembali. Pantulan gelombang tersebut akan diterima oleh piezoelektrik (receiver) dan kemudian sensor akan mengkalkulasi perbedaan antara waktu pengiriman dan waktu gelombang pantul yang akan diterima. 


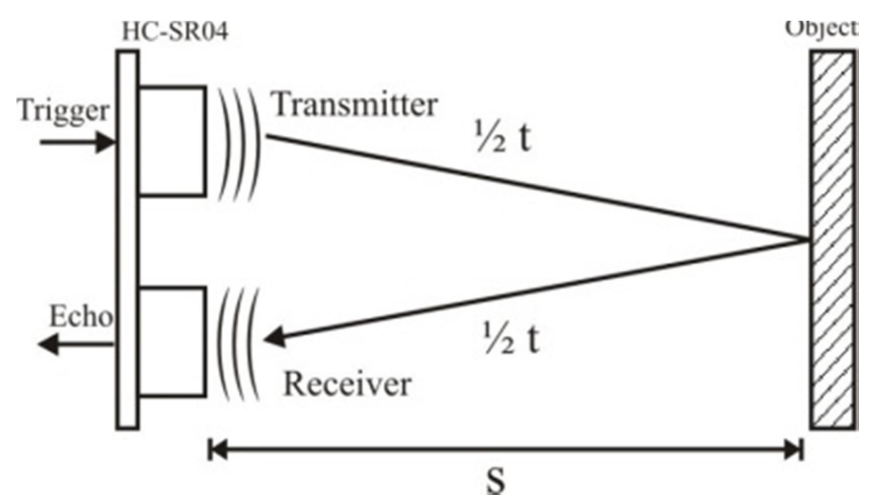

Gambar 6. Rangkaian Sensor Ultrasonik HC-SR04

Berdasarkan pengukuran jarak menggunakan sensor ultrasonik HC-SR04 yaitu ketika pulsa trigger diberikan pada sensor, transmitter akan mulai memancarkan gelombang ultrasonik, pada saat yang sama sensor akan menghasilkan output TLL transisi naik menandakan sensor mulai menghitung waktu pengukuran, setelah receiver menerima pantulan yang dihasilkan oleh suatu objek maka pengukuran waktu akan dihentikan dengan menghasilkan output TTL transisi turun. Pemilihan HCSR04 sebagai sensor jarak yang akan digunakan pada penelitian ini karena memiliki fitur diantaranya kinerja yang stabil, pengukuran jarak yang akurat dengan ketelitian $0,3 \mathrm{~cm}$, pengukuran maksimum dapat mencapai 4 meter dengan jarak minimum $2 \mathrm{~cm}$, ukuran yang ringkas dan dapat beroperasi pada level tegangan TTL.

\section{Modul Relay 4 Channel}

Penggunaan Relay akan berfungsi sebagai penggerak kontak saklar, sehingga dengan menggunakan arus listrik yang kecil atau low power dapat menghantarkan arus litrik yang memiliki tegangan lebih tinggi. Seperti halnya relay yang menggunakan electromagnet $5 \mathrm{~V}$ dan $50 \mathrm{~mA}$ mampu menggerakkan Armature relay (yang berfungsi sebagai saklarnya) untuk menghantarkan listrik 220V 2A tersebut.

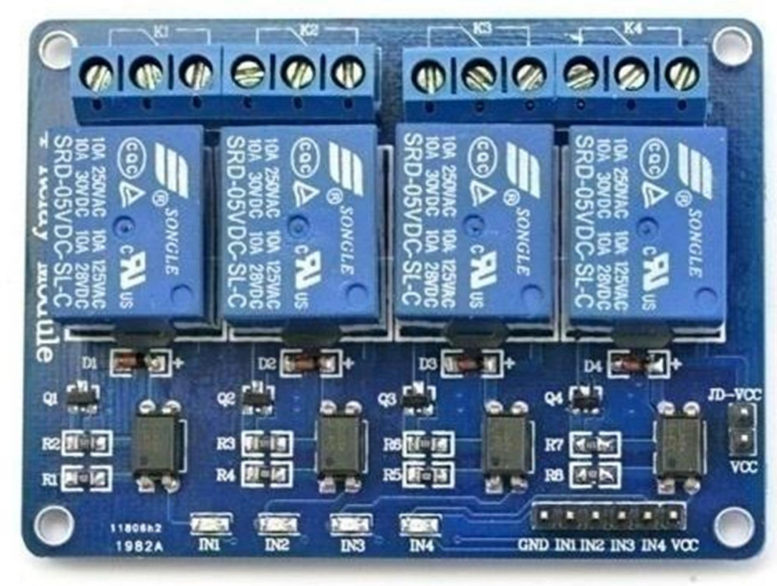

Gambar 7. Modul Relay 4 Channel

Pada Modul Relay 4 Channel ini mengontrol Arduino/Microcontroller dan dilengkapi dengan optocoupler untuk melindungi pin digital microcontroller apabila terjadi dari arus balik.

\section{E. Lampu LED}

Penggunaan LED sebagai salah satu komponen elektronika yang terbuat dari bahan semi konduktor jenis dioda yang mempu mengeluarkan cahaya. Sama halnya dengan dioda, tetapi pada LED elektron menerjang sambungan P-N (Positif-Negatif). 


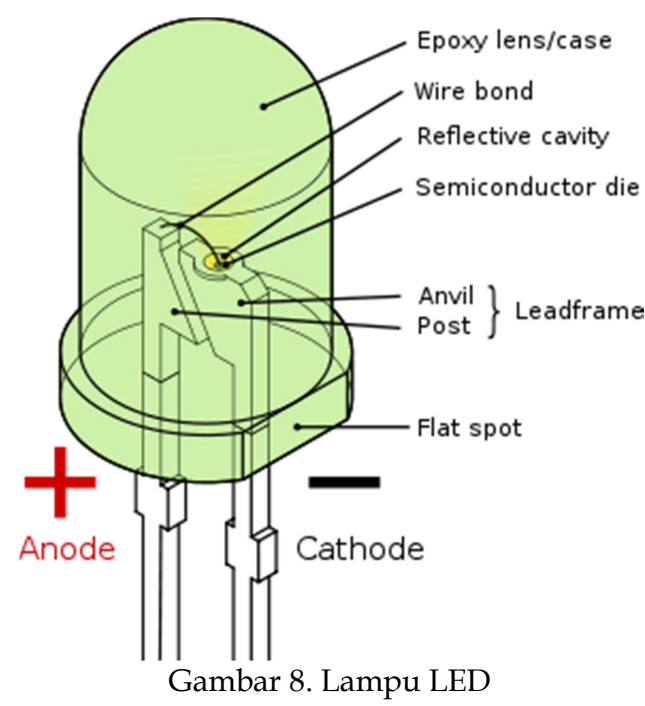

Untuk cara kerja LED apabila ada arus listrik mengalir dari anoda ke katoda, maka LED tersebut sedang menyala. Pemasangan kutub LED tidak boleh terebalik karena apabila terbalik kutubnya maka LED tersebut tidak akan menyala.

\section{F. Step Down LM 2596}

Penggunaan Step LM2596 akan berfungsi sebagai pengkonversi tegangan DC ke DC yang dilengkapi dengan IC penurun dan penaik tegangan. Pada LM2596 tegangan di konversi dan bisa disesuaikan dengan cara memutar bagian pengaturan untuk menurunkan atau menaikan tegangan.

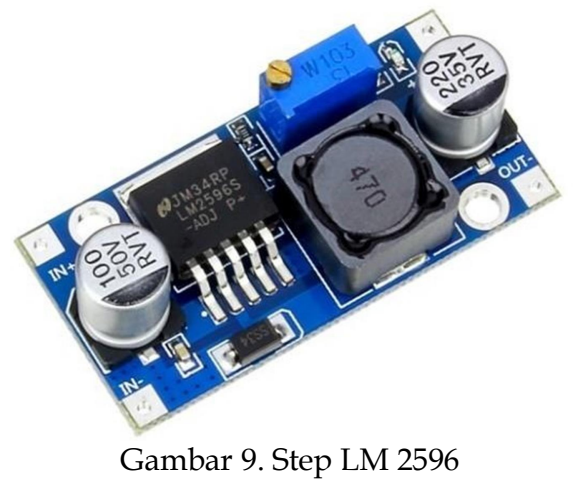

\section{G. Baterai}

Penggunaan baterai untuk mikrokontroler yaitu 9 volt. Ketika terminal terletak bersebelahan satu sama lain di bagian atas baterai. Jika Anda menghubungkan kabel antara dua terminal, maka elektron akan mengalir dari ujung negatif ke ujung positif.

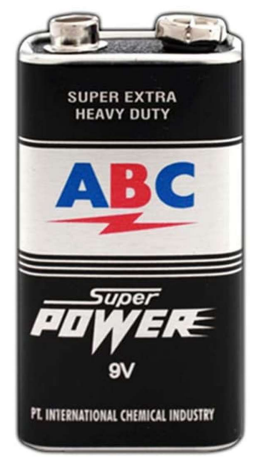

Gambar 10. Baterai 


\section{H. Power Supply (Adaptor)}

Penggunaan Power Supply (Adaptor) akan berfungsi adalah untuk mengubah tegangan AC yang tinggi menjadi DC yang rendah.

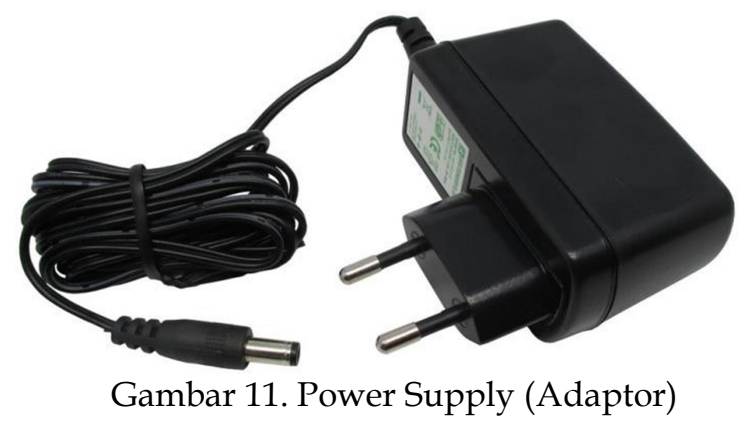

\section{METODE}

\section{A. Perancangan Diagram Blok Sistem}

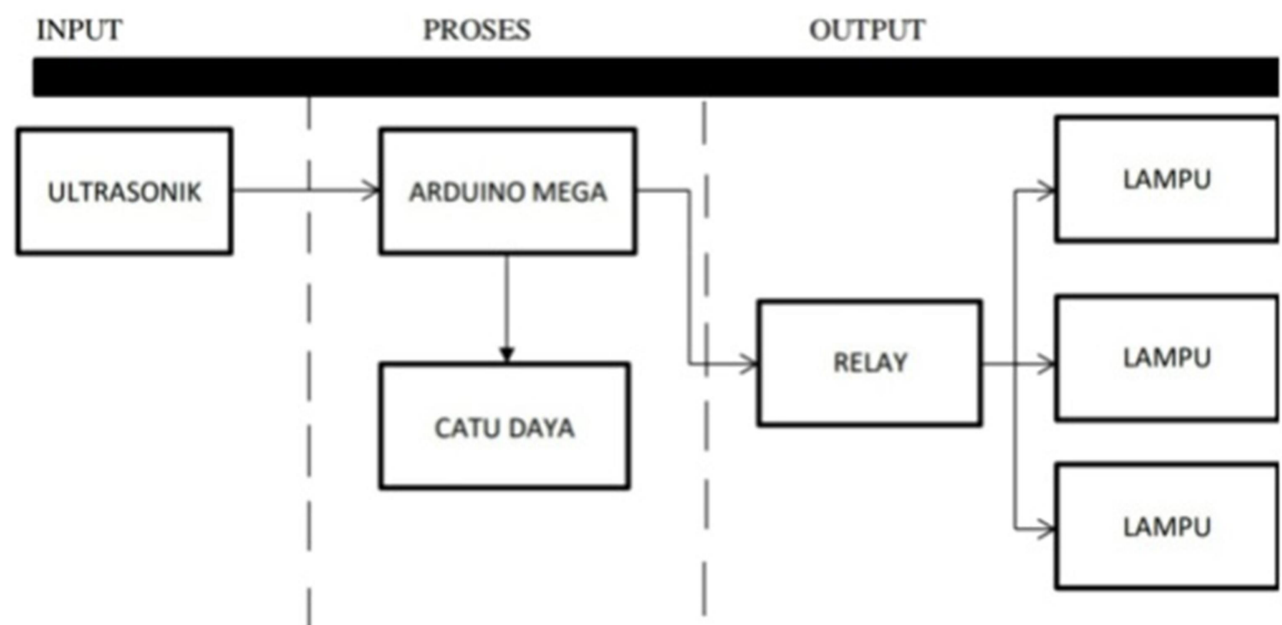

Gambar 12. Blok Diagram Sistem

Berdasarkan diagram blok sistem terdapat Arduino Mega yang berfungsi untuk mengendalikan semua perangkat pada sistem, yang terdiri dari Ultrasonik sebagai Input dalam mendeteksi objek yang bergerak dan menghidupkan lampu dijalan secara otomatis apabila adanya gerakan maka lampu akan hidup dan bekerja secara otomatis. Sehingga fungsi dari ultrasonik tersebut dapat berpengaruh terhadap gerakan yang akan melewati setiap lampu dimana jika objek melewati lampu 1. Maka lampu satu akan mengalami keadaan menyala secara otomatis dan jika objek sudah lewati lampu 1 maka lampu 1 akan mengalami keadaan mati otomatis kemudian berlanjut ke lampu 2 dan lampu 2 akan hidup otomatis.

Setelah membuat blok diagram sistem maka tahap selanjutnya melakukan perancangan hardware sistem. Dalam perancangan hardware, dilakukan beberapa proses diantaranya perancangan miniatur rumah kaca, perancangan masing-masing komponen, dan pengkabelan (wiring).

Selanjutnya melakukan proses perancangan desain miniatur lampu jalan otomatis dengan menggunakan bahan akrilik sebagai alas, Acrylic yang digunakan ketebalannya $2 \mathrm{~mm}$ dengan panjang $50 \mathrm{~cm}$ dan lebar $40 \mathrm{~cm}$. serta miniatur tinggi lampu $10 \mathrm{~cm}$. Sampai kepada miniatur pohon $6 \mathrm{~cm}$ berskala 1:100 sebanyak 4 buah.

Kemudian melakukan perencanaan rangkaian yang dimana saat sensor Ultrasonik menerima gerakan dari objek cahaya lampu keadaan menyala otomatis, tetapi jika objek sudah melewati lampu maka lampu berikutnya yang akan menyala secara otomatis. 
Sampai kepada melakukan proses perancangan rangkaian lampu jalan otomatis yang bertujuan untuk menghubungkan masing-masing komponen ke Arduino Mega serta Sensor Ultrasonik sebagai Sensor jarak yang mendeteksi objek agar dapat menghidupkan lampu secara otomatis.

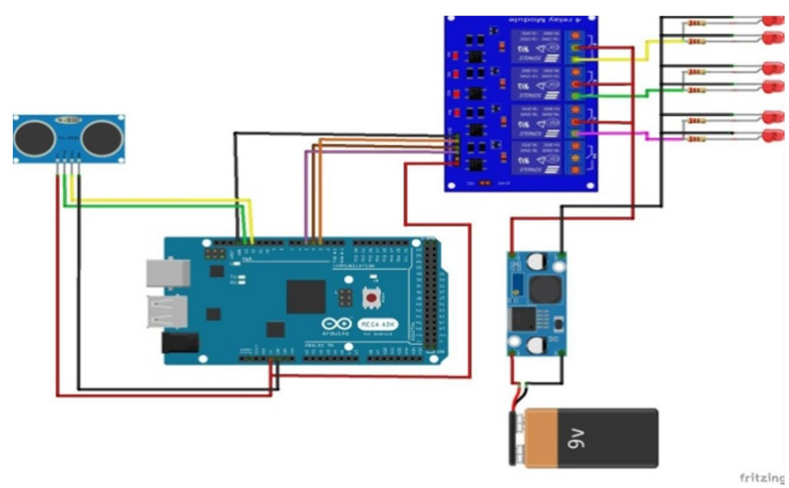

Gambar 13. Sistem Rangkaian Lampu Jalan Otomatis

Untuk Sensor Ultrasonik yang sudah terhubung ke Arduino Mega bertujuan mengatur jarak objek yang dibaca oleh sensor dan kemudian cara kerja LED dapat diatur jarak sesuai kebutuhan rancang bangun tersebut.

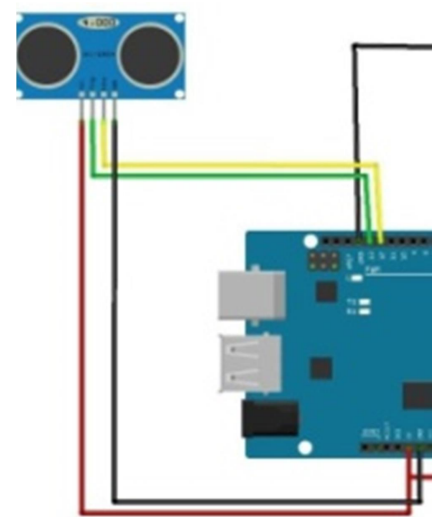

Gambar 14. Rangkaian Arduino Mega dan Sensor Ultrasonik

Untuk Relay yang sudah terhubung ke Arduino Mega sebagai alat pengendali, dimana nantinya lampu akan keadaan mati dan keadaan hidup sesuai kebutuhan Rancang Bangun disini dengan menggunakan 3 Relay untuk LED 1, 2, dan 3.

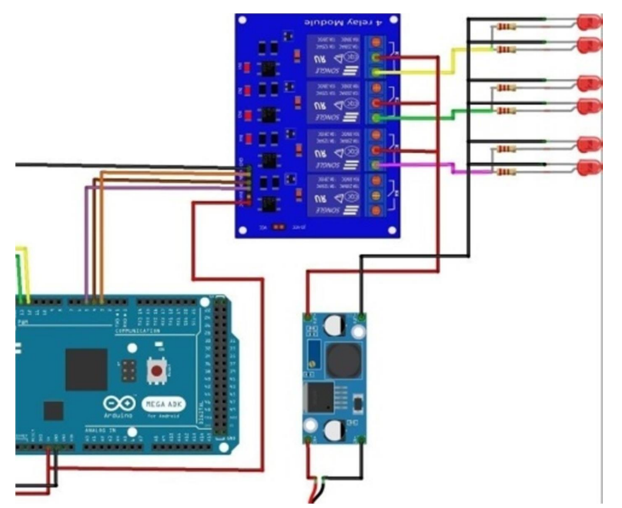

Gambar 15. Rangkaian Arduino Mega dan Relay

Kemudian untuk LM 2596 ini akan berfungsi sebagai menurukan tegangan dari Relay menjadi 5v yang sedang terhubung ke setiap LED yang nantinya akan dikendalikan oleh Relay untuk menyalakan lampu dan matinya lampu secara otomatis. 


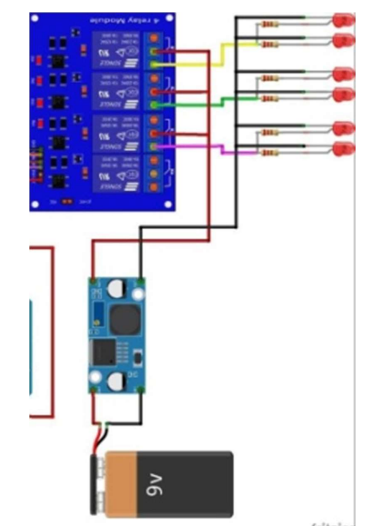

Gambar 16. Rangkaian Relay To LM 2596 dan LED

Maka dari itu untuk bentuk flowchart dari proses perancanga yang akan dibua sesuai dengan yang dibutuhkannya tersebut.

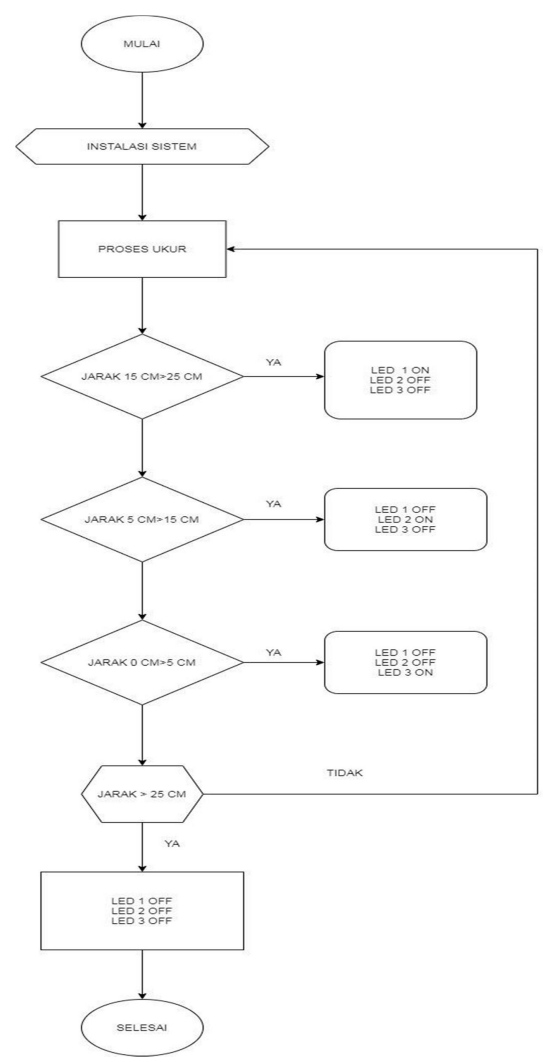

Gambar 17. Flowchart

Berdasarkan dari flowchart diatas, Arduino Mega dapat menginstalasi sistem Sensor Ultrasonik, Relay dan LM 2596. Setelah terinisialisasi pada Sensor Ultrasonik dapat bekerja untuk memantulkan jarak objek yang ada didepan atau kendaraan kemudian dapat dipantulkan kembali sehingga bisa mengatur lampu menjadi keadaan menyala terhadap rancang bangun tersebut. Kemudian untuk proses ukurnya dapat berlangsung sesuai kondisi jarak. Jika jarak $15 \mathrm{~cm}>25 \mathrm{~cm}$ maka hasilnya LED 1 ON , LED 2 OFF, LED 3 OFF jika jarak $5 \mathrm{~cm}>15 \mathrm{~cm}$ maka hasilnya LED 1 OFF, LED 2 ON LED 3 OFF. Dan jika jarak $0 \mathrm{~cm}>5 \mathrm{~cm}$ maka hasilnya LED 1 OFF, LED 2 OFF, LED 3 ON. Dan jika objek berada di jarak $>25 \mathrm{~cm}$ maka semua LED akan mati, jika TIDAK maka akan kembali ke proses ukur. Sehingga jarak yang sudah tentukan oleh sensor ultrasonik melalui program akan dapat menghidupkan LED dengan menggunakan baterai yang diatur oleh LM 2596 sebesar $5 \mathrm{v}$. 
(online), Hal 43 - 54,

\section{HASIL DAN PEMBAHASAN}

Pengujian pengukuran Sensor Ultrasonik ini akan dilakukan dengan tujuan untuk mengetahui jarak pada objek yang akan bergerak.

Tabel 1. Pengamatan dan Analisa Percobaan

\begin{tabular}{rcccc}
\hline \multicolumn{1}{c}{ No } & Jarak & LED 1 & LED 2 & LED 3 \\
\hline 1 & $0 \mathrm{~cm}-25 \mathrm{~cm}$ & ON & OFF & OFF \\
2 & $0 \mathrm{~cm}-15 \mathrm{~cm}$ & OFF & ON & OFF \\
3 & $0 \mathrm{~cm}-5 \mathrm{~cm}$ & OFF & OFF & ON \\
4 & $>25 \mathrm{~cm}$ & OFF & OFF & OFF \\
\hline
\end{tabular}

Berdasarkan hasil pengamatan dan analisa percobaan tersebut, maka selanjutnya bentuk gambar miniatur rancang bangun lampu penerangan jalan otomatis yang dibuat sedemikian rupa.

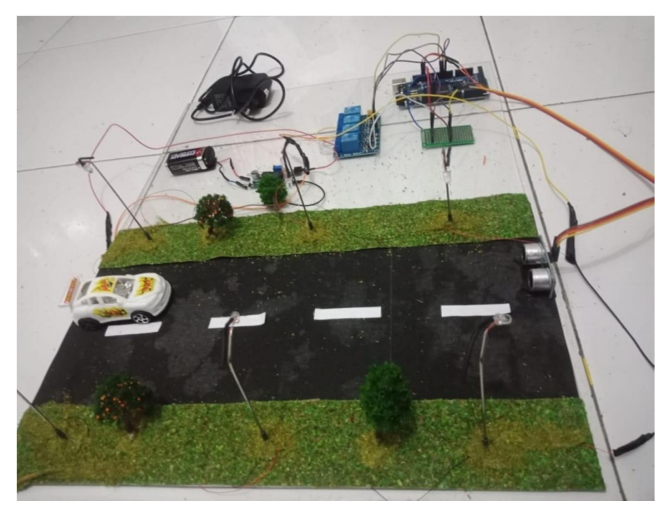

Gambar 18. Keseluruhan Rancang Bangun

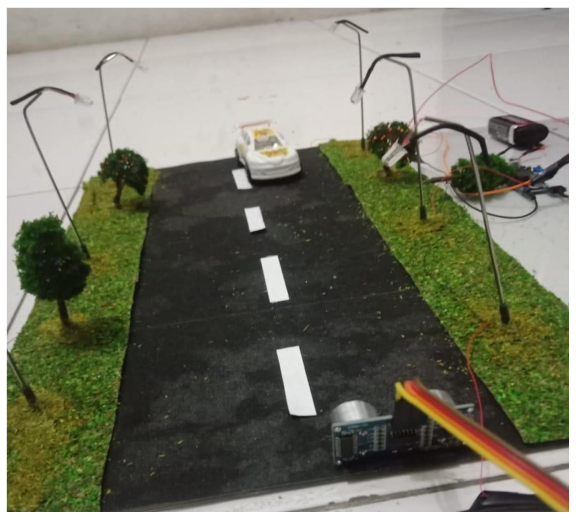

Gambar 19. Miniatur Rancang Bangun Jalan dan Lampu LED

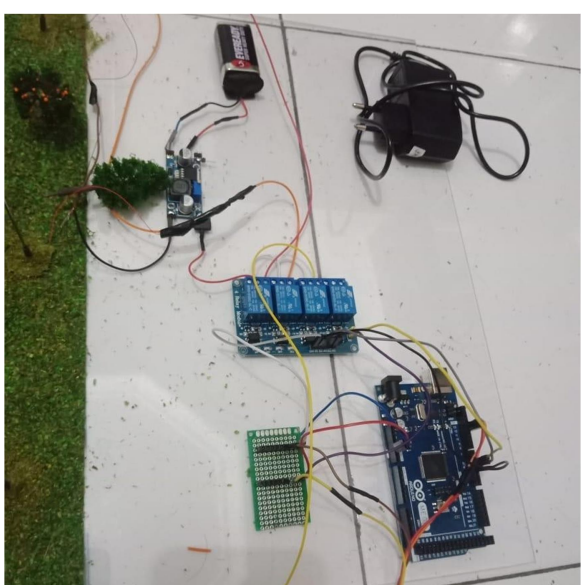

Gambar 20. Komponen-Komponen Rancang Bangun 
Hasil Percobaan Pertama :

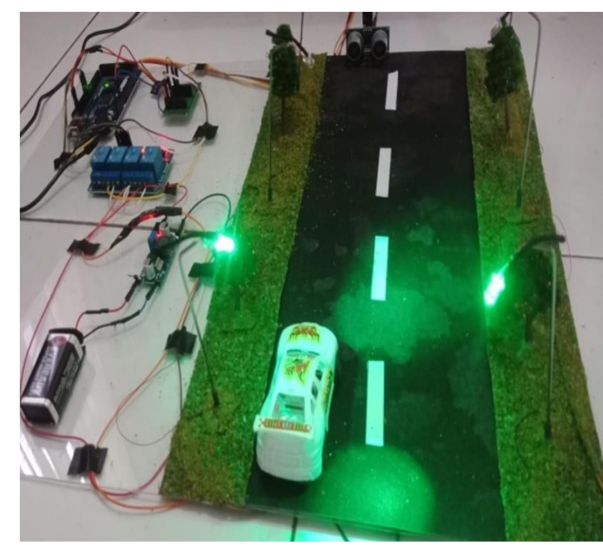

Gambar 21. Percobaan Pertama

Berdasarkan hasil dari percobaan pertama, bahwasanya lampu LED 1 dalam keadaan menyala dari jarak $0 \mathrm{~cm}-25 \mathrm{~cm}$ sedangkan LED 2 dan LED 3 dalam keadaan Mati.

Hasil Percobaan Kedua :

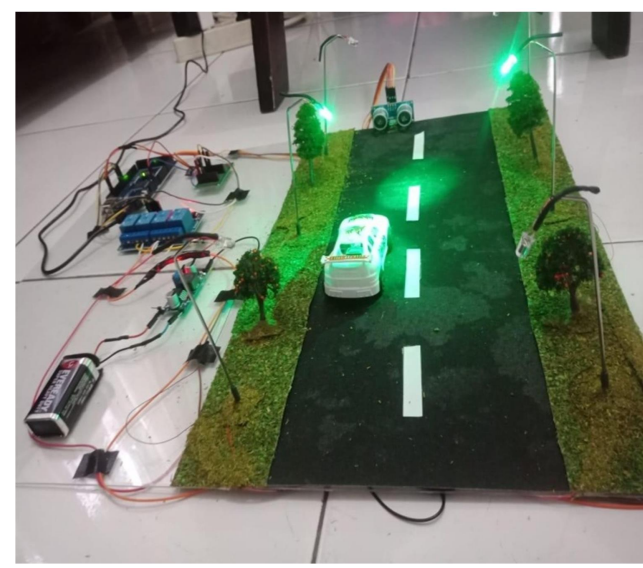

Gambar 22. Percobaan Kedua

Berdasarkan hasil dari percobaan kedua, bahwasanya lampu LED 2 dalam keadaan menyala dari jarak $0 \mathrm{~cm}-15 \mathrm{~cm}$ sedangkan LED 1 dan LED 3 dalam keadaan Mati.

Hasil Percobaan Ketiga :

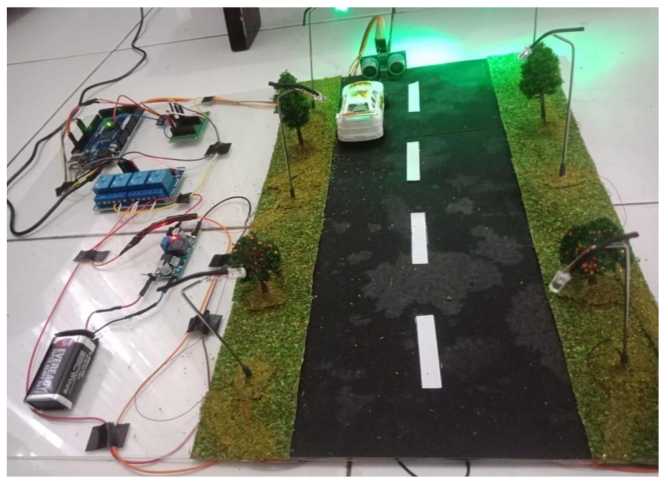

Gambar 23. Percobaan Ketiga

Berdasarkan hasil dari percobaan pertama, bahwasanya lampu LED 3 dalam keadaan menyala dari jarak $0 \mathrm{~cm}-5 \mathrm{~cm}$ sedangkan LED 1 dan LED 2 dalam keadaan Mati. 
Hasil Percobaan Keempat :

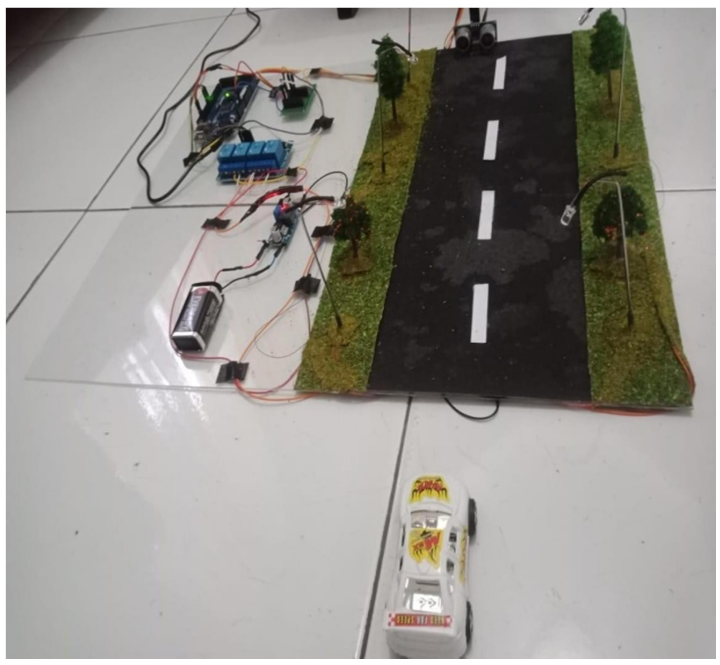

Gambar 24. Percobaan Keempat

Berdasarkan hasil dari percobaan kedua, bahwasanya objeknya berjarak $>25 \mathrm{~cm}$ sehingga LED 1, LED 2 dan LED 3 sama-sama dalam keadaan Mati.

\section{KESIMPULAN}

Berdasarkan hasil dan pembahasan melalui pada pengujian dan percobaan lampu penerangan jalan otomatis sistem tersebut, maka dapat disimpulkan bahwa Penggunaan dari Sensor Ultrasonik bertujuan untuk menstral sistem, karena sensor Ultrasonik dapat membaca jarak pada objek untuk menghidupkan secara otomatis. Penggunaan Lampu LED akan dapat bekerja secara otomatis, apabila objek sudah melewati atau berada pada jarak yang ditetapkan terhadap sensor Ultrasonik. Penggunaan sistem ini akan menghasilkan waktu selama sistem dapat terhubung dengan sumber tegangan.

\section{DAFTAR PUSTAKA}

[1] Widodo, Dr.Ir. Thomas Sri, DEA, Dipl.Ing. 2002. Elektronika Dasar. Salemba Teknika: Jakarta.

[2] Kristian, Matius. 2014. Perancangan Penerangan Lampu Jalan Otomatis Berbasis Arduino Mega2560. Erlangga.

[3] Anggreny, Andri. 2016. Perancangan dan Pembuatan Alat Pengendali Lampu Otomatis Dengan Menggunakan Relay Dan Sensor Ultrasonik Berbasis Arduino Mega. Politeknik Negeri Semarang.

[4] Barmawi, Malvino. 1991. Prinsip- Prinsip Elektronika. Edisi 3. Jilid 2.Erlangga.

[5] Daryanto. 2012. Teknik Dasar Elektronika Komunikasi. Cetakan ke- 1. Bandung : Sarana Tutorial Nurani Sejahtera.

[6] https://www.andalanelektro.id/2018/09/cara-kerja-dan-karakteristik-sensor- ultrasonichcsr04.html.

[7] http://ekorendisatrio.blogspot.com/2013/04/mengenal-lampu-led.html.

[8] https://www.autoexpose.org/2017/09/fungsi-cara-kerja-relay.html.

[9] https://docplayer.info/73868392-Tugas-akhir-perencanaan-penerangan-jalan- umum-jalanjendral-sudirman-kota-toboali-kabupaten-bangka-selatan.html. 